\title{
The origin of lamination in stalagmites from Katerloch Cave, Austria: Towards a seasonality proxy
}

Ronny BoCH ANd ChRISTOPH SPÖTL

Institute of Geology and Paleontology, University of Innsbruck, Austria; Ronny.Boch@uibk.ac.at

Macro- to microscopic layering, comparable to that in polar ice, corals and some lake and marine sediments, is common in many speleothems. Laminated stalagmites and flowstones occur from the high- and mid-latitudes down to low-latitude cave sites. In many cases, the observed lamination is demonstrably of annual origin and is an expression of seasonality (Broecker et al., 1960; Frisia et al., 2003). Locally, however, event laminae on sub-annual to multi-annual timescales are present, being stochastic or periodical in nature (e.g., Baker et al., 2002). Various material properties give rise to macro- and microscopic lamination patterns in speleothems, most notably changes in mineralogy (Railsback et al., 1994) and crystal fabric (Kendall and Broughton, 1978; Frisia et al., 2000), as well as the abundance and distribution of pores, fluid and particle inclusions or organic components. The latter, when exposed to a source of blue or ultraviolet light, cause fluorescence, which is a useful tool to study lamination patterns (e.g., Meyer et al., 2006).

Laminated speleothems have received increasing attention in recent

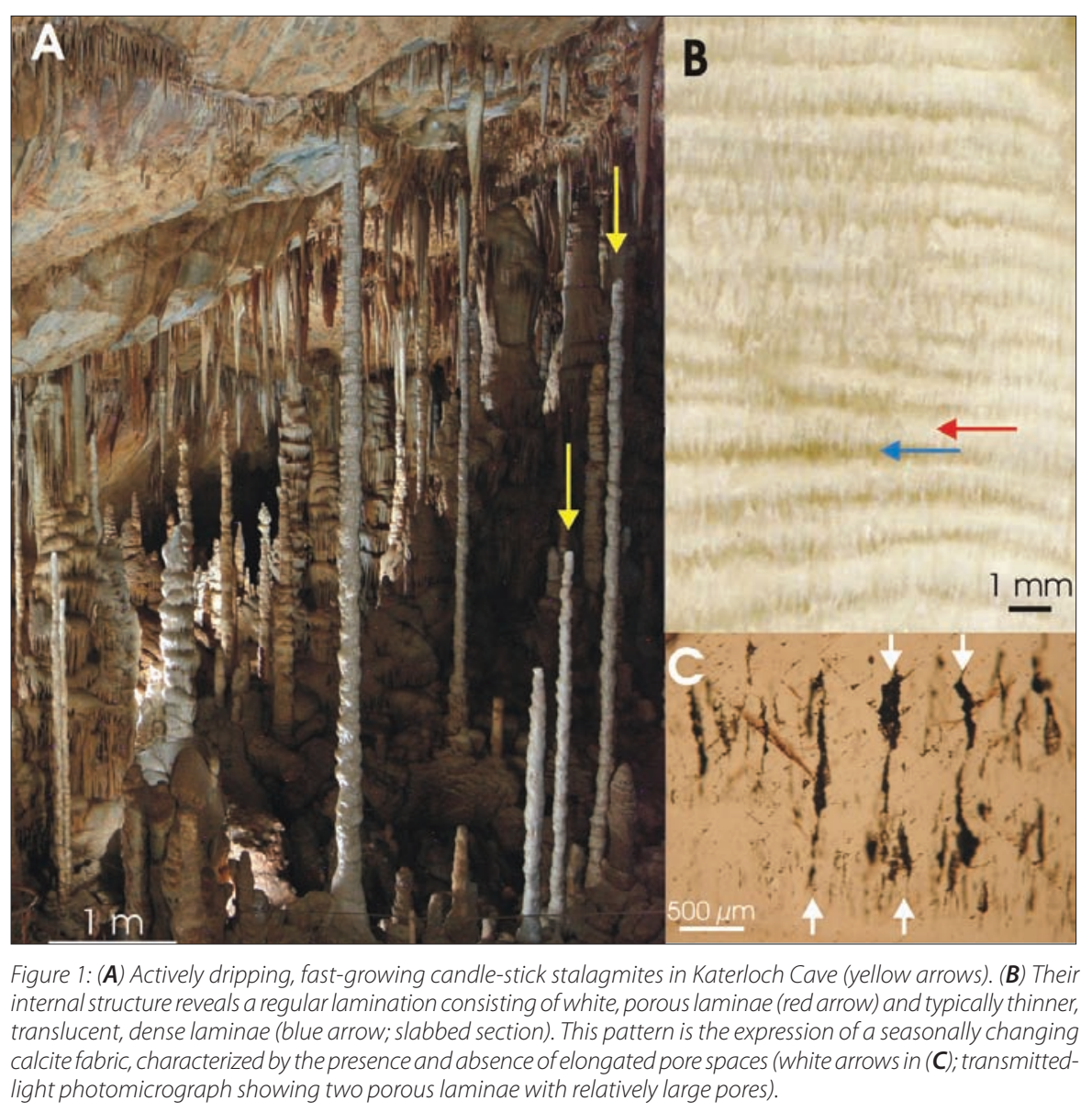

Figure 1: (A) Actively dripping, fast-growing candle-stick stalagmites in Katerloch Cave (yellow arrows). (B) Their internal structure reveals a regular lamination consisting of white, porous laminae (red arrow) and typically thinner, translucent, dense laminae (blue arrow; slabbed section). This pattern is the expression of a seasonally changing calcite fabric, characterized by the presence and absence of elongated pore spaces (white arrows in (C); transmittedlight photomicrograph showing two porous laminae with relatively large pores). years, as they provide very highly resolved paleoenvironmental proxy records for the terrestrial realm when combined with high-precision U-Th dating. Exploitation of their full potential for paleoscientific reconstructions requires a thorough calibration and validation of speleothem lamina proxy data, which ideally should be performed for each cave site using a combination of multi-annual cave monitoring and comparison with nearby meteorological data (e.g., Mattey et al., 2008). Constantdiameter (or candle-stick; see Fig. 1A) stalagmites are best suited for lamina-based paleoclimate studies because their morphology indicates rather constant growth, and the lamina thickness directly reflects the amount of annually precipitated carbonate, which is controlled by the prevailing environmental conditions.

In order to better understand the mechanism of lamina development and to assess the paleoenvironmental potential of annually layered stalagmites, Katerloch Cave in Austria was monitored over a period of three years. A holistic approach was used, which comprised analyses of soil air, cave air, drip water, modern calcite precipitates on artificial substrates and stalagmite samples.

\section{Seasonally controlled lamination in Katerloch stalagmites}

Located at the south-eastern fringe of the European Alps (900 m asl), Katerloch Cave hosts abundant stalagmites of the candlestick morphology, several of which are actively growing (Fig. 1A). Eight recovered samples of Holocene, Last Glacial period and Last Interglacial ages reveal a rather uniform macroscopic lamination pattern consisting of white, porous calcite layers and typically thinner, translucent and dense calcite layers (Fig. 1B). This regularly alternating pattern is caused by changes in the calcite fabric, in particular by the abundance of elongated pore spaces commonly containing fluid inclusions (Fig. 1C). The white, porous (inclusion-rich) laminae are further characterized by enhanced vertical growth and thinning towards the edges, whereas the translucent, dense laminae show a more constant thickness along individual growth layers. A similar type of lamination was also reported from speleothems elsewhere (Genty and Quinif, 1996; Yadava et al., 2004; Mattey et al., 2008). U-Th dating confirms the annual origin of the lamination in several Katerloch stalagmites. Stable $C$ isotope values obtained from the stalagmites follow the lamination pattern, whereby high values typically coincide with the translucent, dense laminae and low values correlate with the white, porous laminae (Fig. 2).

The origin of this pattern is linked to the seasonally changing airflow in this cave (Boch, 2008): during the warm season the $\mathrm{pCO}_{2}$ builds up in the cave, whereas the large temperature gradient between the outside atmosphere and the interior cave air results in increased ventilation during the cold season. Low cave air $\mathrm{CO}_{2}$ concentrations during the latter season, as a result of enhanced exchange with the outside atmosphere, give rise to enhanced $\mathrm{CO}_{2}$-degassing of the drip waters and high calcite supersaturation. This results in a change of the crystal fabric (from white, porous to translucent, dense) and an increase in the $C$ isotope values in drip waters and dense calcite. In contrast, stable $\mathrm{H}$ and $\mathrm{O}$ isotope analyses reveal no seasonal variations in the drip waters, indicating discharge from a well-mixed 


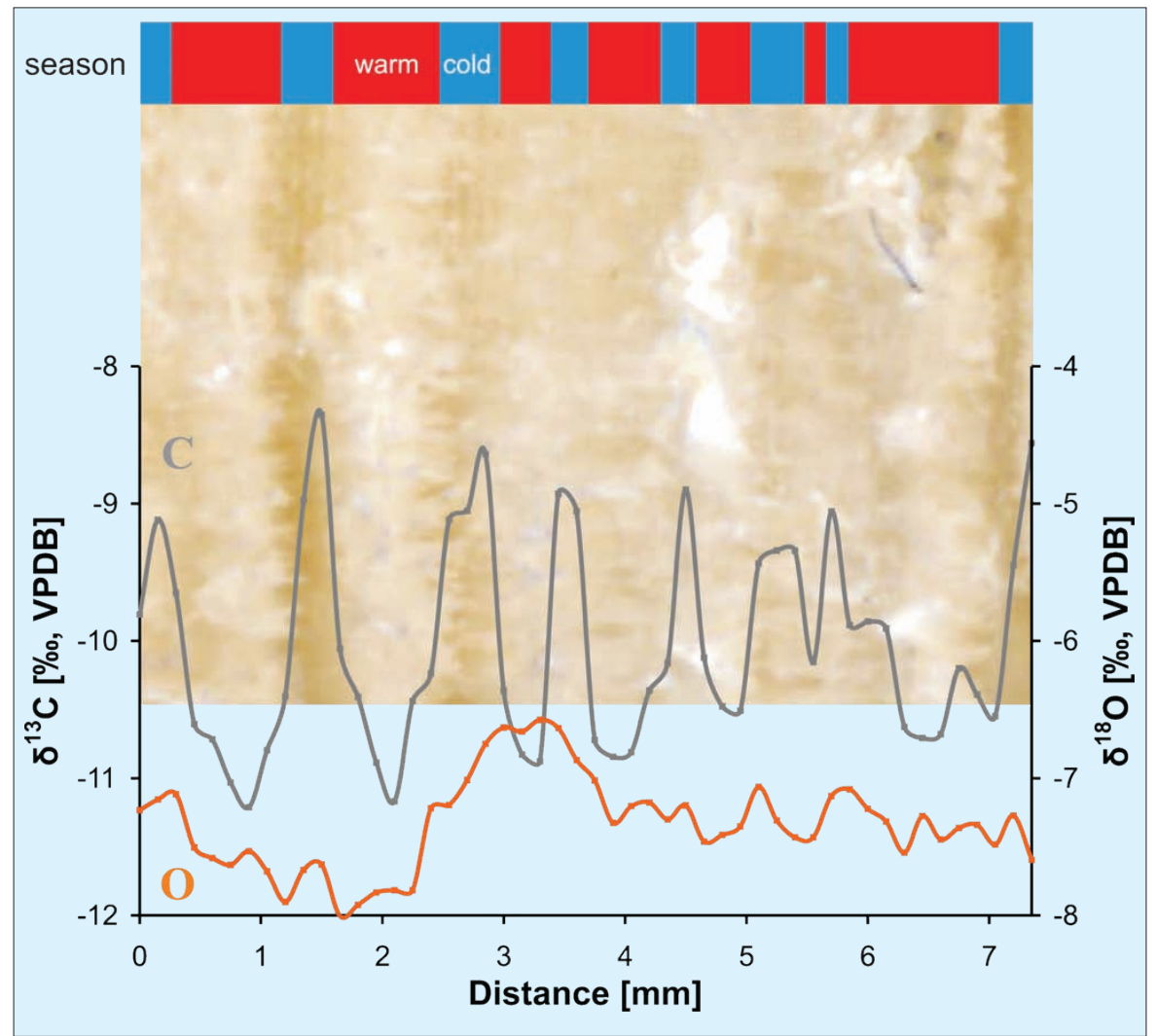

Figure 2: Example of the stable isotopic composition of a laminated Last Interglacial stalagmite from Katerloch Cave: White, porous laminae typically coincide with low calcite $\delta^{13} \mathrm{C}$ values and cave monitoring indicates that these laminae form during the warm season when cave air and drip water C isotope values are low (sluggish air exchange, relatively high $\mathrm{CCO}_{2}$ level). Translucent, dense laminae show high $\mathrm{C}$ isotope values and form during the cold season (enhanced air exchange, low pCO, level and kinetically controlled C isotope fractionation). The $O$ isotopes, in contrast, are unaffected by these seasonal oscillations and record multi-annual changes.

aquifer, i.e., the mean residence time of the water in the vadose zone (the zone between the land surface and the water table) is well above one year. Likewise, $\mathrm{O}$ isotope data from the stalagmites do not follow the high-frequency (seasonal) variability of the $C$ isotope data but show rather gradual, multi-annual changes (Fig. 2). In addition to the seasonal air-exchange dynamics (driven by temperature contrasts), the lamina thickness data are also a record of the amount of meteoric precipitation (or, more precisely speaking, of the net infiltration) in the catchment area. This is consistent with other studies including cold season, the lamination is primarily a proxy of the intensity of winter air circulation in the cave and, hence, of winter air temperature. For example, long and cold winters give rise to relatively thick, translucent and dense laminae showing high $C$ isotope values. In addition, the lamina thickness also reflects the amount of precipitation that recharges the karst aquifer. Wet years promote thick laminae due to increased drip rates (enhanced ionic supply). The relative thickness, however, of summer and winter laminae will eventually also depend on the specific flow conditions at a particular drip site. This study therefore highlights the value of cave monitoring in order to understand the speleothem growth dynamics at a specific cave site, which is an indispensible requirement for exploiting lamination patterns as a quantitative seasonal climate proxy. Given the scarcity of reliable winter proxy data in most currently available terrestrial paleoclimate archives, dynamically ventilated caves such as Katerloch offer a potentially unique opportunity to fill this gap.

\section{References}

Baker, A., Genty, D., Dreybrodt, W., Barnes, W.L., Mockler, N.J., and Grapes, J., 1998: Testing theoretically predicted stalagmite growth rate with recent annually laminated samples: Implications for past stalagmite deposition, Geochimica et Cosmochimica Acta, 62: 393-404.

Frisia, S., Borsato, A., Fairchild, I.J., and McDermott, F., 2000: Calcite fabrics, growth mechanisms and environments of formation in speleothems from the Italian Alps and southwestern Ireland, Journal of Sedimentary Research, 70: 1183-1196.

Kaufmann, G., 2003: Stalagmite growth and palaeo-climate: the numerical perspective, Earth and Planetary Science Letters, 214 251-266.

Mattey, D. Lowry, D., Duffet, J., Fisher, R., Hodge, E. and Frisia, S., 2008 A 53 year seasonally resolved oxygen and carbon isotope record from a modern Gibraltar speleothem: reconstructed drip water and relationship to local precipitation, Earth and Planetary Science Letters, 269: 80-95.

Meyer, M., Faber, R. and Spötl, C., 2006: The WinGeol Lamination Tool: new software for rapid, semi-automated analysis of laminated climate archives, The Holocene, 16: 753-761.

\title{
Precipitation records of the last century reconstructed from annual growth-rate parameters of two Ethiopian stalagmites
}

\author{
Asfawossen Asrat ${ }^{1}$ and Andy BakeR ${ }^{2}$ \\ 'Department of Earth Sciences, Addis Ababa University, Ethiopia; asrata@geol.aau.edu.et \\ ${ }^{2}$ School of Geography, Earth and Environmental Sciences, University of Birmingham, UK; a.baker.2@bham.ac.uk
}

The Ethiopian highlands, located in the central section of the horn of Africa, are one of Africa's rain sensitive regions where monsoon rainfall variability plays a key role in triggering frequent droughts. The region is subject to the seasonal migration of the Inter-Tropical Convergence Zone (ITCZ) and is very sensitive to monsoon variability (Seleshi and Zanke, 2004). The main rainy season (July-September) oc- curs when the northward movement of the ITCZ dominates the airflow, while the spring rainy season (March-May) coincides with the southward migration of the ITCZ. 